\title{
CIVILIZAÇÃO, TRONCO DE ESCRAVOS: UM PROTESTO RADICAL PELA LIBERDADE INTEGRAL
}

Nabylla Fiori de Lima ${ }^{1}$

Resenha do livro: MOURA, Maria Lacerda de. Civilização, tronco de escravos. Patrícia Lessa e Cláudia Maia (orgs.). São Paulo/SP: Editora Entremares, 2020.

Recebido em: 29/11/2020

Aprovado em: 30/12/2020

Chamamos de visionárias e dizemos que estavam à frente de seu tempo àquelas que, atentas às questões da sua época, teciam críticas que nos servem dezenas ou mesmo centenas de anos depois. Entretanto, trata-se, muitas vezes, de pessoas que souberam analisar tão bem o presente que nele captaram as centelhas que acendem outros fogos no futuro. Assim é a obra de Maria Lacerda de Moura (1887-1945) e é assim que recebemos a nova edição lançada pela editora Entremares da obra Civilização, Tronco de Escravos, organizada pelas pesquisadoras e professoras Patrícia Lessa e Cláudia Maia, ambas historiadoras com amplas pesquisas relacionadas às lutas das mulheres e com trabalhos já desenvolvidos sobre a anarquista brasileira.

A editora Entremares, cuja trajetória se iniciou no ano de 2017, não é uma editora que circula em grandes livrarias, e tem feito um ótimo trabalho de resgate de obras do passado ao passo que também traz publicações recentes de autores libertários. Civilização, tronco de escravos é a segunda obra de Maria Lacerda de Moura lançada pela editora, que também já publicou uma nova edição de Fascismo: filho dileto da Igreja e do Capital (2018) e recentemente lançou a obra Amor \& Libertação em Maria Lacerda de Moura (2020), de Patrícia Lessa. Civilização... integra a Coleção Astrolábio da editora, que tem como objetivo trazer a filosofia e o pensamento crítico como instrumentos para navegar na busca de "outros olhares, outra moral, outros horizontes".

\footnotetext{
${ }^{1}$ Doutoranda em Tecnologia e Sociedade, Pesquisadora do Grupo de pesquisa Ciências Humanas, Tecnologia e Sociedade - CHTS, na linha Pensamento Anarquista em Ciência e Tecnologia. Universidade Tecnológica Federal do Paraná-PR, Brasil. E-mail: nabyllafiori@gmail.com. ORCID: https://orcid.org/0000-0003-4313-7050.
} 
O projeto gráfico e a diagramação foram responsabilidade de Adriano Skoda. A capa retoma uma litografia do artista suíço Théophile-Alexandre Steinlen (1859-1923). Em L'exode (1915), Steinlen retrata o deslocamento das populações marginalizadas após ataques em períodos de guerras, reforçando a crítica de Maria Lacerda de Moura em sua obra.

Maria Lacerda acompanhou a implementação da república no Brasil e esteve em contato com os movimentos operários de seu período, inclusive contribuindo em diversos periódicos. A educadora e escritora brasileira nasceu em Manhuaçu (MG), mas se formou e trabalhou como professora em Barbacena (MG) e se mudou para a capital paulista na década de vinte do século passado. Inicialmente, participou de associações femininas que tinham como uma de suas lutas centrais a reivindicação do sufrágio feminino. Entretanto, percebeu que apesar das diferenças da realidade vivenciada pelas mulheres nas cidades em que passou, a condição de exploração e submissão se repetia. A luta pelo sufrágio universal mostrou-se insuficiente para dar conta dessas questões.

Aproximou-se do anarquismo, sem filiar-se a nenhum programa ou afirmações imutáveis. Sua preocupação com a emancipação humana - e não apenas das mulheres - levoua a críticas profundas sobre a organização da sociedade vigente. Entretanto, na sua percepção acurada do presente, constatou que a revolução se inicia em cada um. Parte de indivíduos que, conscientes da sua responsabilidade na construção coletiva da sociedade e da sua interrelação com os demais indivíduos, modificam-se a si mesmos e constroem outras realidades possíveis.

Suas obras abordam temas diversos. Educação, amor plural (uma forma ainda mais ampla de amor livre), neomalthusianismo, antimilitarismo, espiritualidade, antifascismo além de críticas à sociedade capitalista industrial, ao servilismo voluntário, bem como à crença no progresso científico, tecnológico e econômico. Para a educadora, a aliança entre clero, Estado e capital formavam o emaranhado em que se apoiava a moral burguesa, alimentava o capitalismo e tornava os indivíduos escravos - não somente do trabalho ou da organização social, mas de si mesmos, de modo a sustentarem e reproduzirem a ordem econômica e social em vigência.

Foi nos anos 80 que Maria Lacerda de Moura ressurgiu, tendo a sua biografia recuperada por Miriam Lifchitz Moreira Leite e resultando na obra Outra face do feminismo: Maria Lacerda de Moura (1984). Nos últimos anos, temos acompanhado uma nova onda de resgate das obras da anarquista brasileira, através de pesquisas acadêmicas e reedições de algumas das suas obras.

O lançamento da segunda edição de Civilização, tronco de escravos pousa num presente marcado pelo avanço institucional da direita e um ressurgimento de discursos fascistas que, 
todavia, nunca se apagaram completamente. As críticas de Maria Lacerda permitem-nos olhar para a organização da sociedade de modo amplo e a sua radicalidade é resultado de seu olhar minucioso do presente, que consegue perfurar as questões e chegar nas células mais profundas de cada questão. Embora carregue questões que necessitam de certa atualização, nos fornece bases para a crítica do presente.

A obra em questão teve a sua primeira edição publicada em 1931, pela editora Civilização Brasileira, num período entreguerras e de ascensão do nazi-fascismo. Nela, Maria Lacerda de Moura tece contundentes críticas ao desenvolvimento científico e tecnológico tão atrelado ao desenvolvimento bélico e suas ramificações nas relações sociais.

Civilização, tronco de escravos traz como epígrafe uma frase do filósofo estóico Epicteto: "Vigia a tua vida e não renuncies por nada ao teu livre arbítrio; não imites a esses maus comediantes que só podem cantar em coro". O estoicismo foi uma das grandes referências da autora: é daí a sua noção de "escravo", presente do título da sua obra. O escravo, na concepção dos antigos gregos, diz respeito àqueles que, além de serem governados por outros, em quaisquer dimensão da vida, são também escravos dos próprios prazeres, conforme afirma a autora: “a concepção de liberdade é subjetiva e quem se escraviza à moral social [...] é escravo do ambiente em que vive e servil aos seus próprios prejuízos" (MOURA, 2020, p. 128).

A civilização, para a autora, seria "um Everest de ciência aplicada à indústria, a rolar por sobre a vida de todo gênero humano" (p. 66), produzindo como frutos de seu tronco indivíduos escravos da moral social e de si mesmos, seguidores do "rebanho social". Esse “incêndio voraz denominado civilização ou progresso" (p. 110), baseado no privilégio e na brutalidade, tem na ciência e na tecnologia instrumentos para a dominação e destruição de todos os seres. Radicalmente contrária à vivissecção, contradição entre a ciência e a vida, a libertária lamenta: "Não posso compreender a ciência intervindo no aperfeiçoamento dos meios do homem extorquir dinheiro de outro homem, valendo-se da cirurgia, no atentado à vida fisiológica dos animais sadios” (p. 43). Maria Lacerda não nega o desenvolvimento científico e tecnológico em si, entretanto defende uma "ciência da felicidade", "uma razão que saiba fechar os olhos para sonhar e trazê-los bem abertos para dominar os impulsos inferiores - sem julgar pecado ou imoralidade o que a natureza exige das criaturas para a perfeita harmonia do corpo e da mente" (p. 133).

Aposta, portanto, em uma educação libertária, apresentada em obras anteriores, como por exemplo Renovação (1919) e em diversos artigos em periódicos anarquistas. A educação, nessa sociedade, teria a função de domesticar, "acarneirar" os indivíduos, adormecer a razão e sufocar-lhes a liberdade interior: 
Clero e Capital, Governo e Militarismo dão-se as mãos em uma aliança incondicional através do "freio" religioso posto na mulher e através da educação da infância, na qual a sabedoria sacerdotal põe toda a sua ciência maquiavélica, amoldando, cinzelando, burilando e imprimindo na alma da criança e da juventude o selo de infame que azinhavra as consciências, amordaça a mente, envenena os sentimentos de prejuízos e convenções e ídolos que constituem o maior e mais sério empecilho à evolução humana (p. 108).

A organização social capitalista é descrita pela educadora como um "vasto bordel em que se compram e vendem todos os sentimentos e as mais nobres aspirações, o Amor e a Consciência" (p. 30). A prostituição também recebe duras críticas por parte de Maria Lacerda, que acusa a moral burguesa que institui o casamento como norma, ao passo que subjuga outras mulheres ao trabalho, tão necessário à moral burguesa, da prostituição. Além disso, valorizam a virgem, mas riem da "solteirona". Sem hierarquizar os problemas sociais, para a anarquista brasileira, o cafetão seria tão condenável quanto os acionistas das usinas de guerra.

$\mathrm{Na}$ relação que aponta entre Estado, clero e capital, Moura cita o general inglês J.H.Morgan, para quem "a guerra só desaparecerá quando deixar de ser um negócio" (p. 85). Criticou severamente o interesse das finanças internacionais nos conflitos bélicos, constituindo o que ela chamou de "Internacional Armamentista". Os fabricantes de armas, aponta a autora, muitas vezes lucram com conflitos em seus próprios países. No mesmo sentido, o desenvolvimento da indústria bélica obriga o operário a ganhar seu pão fabricando armas que serão utilizadas para atacá-lo e a seus irmãos, na intenção do Estado de assegurar a “ordem” e a dominação.

Contrária às revoluções violentas, Maria Lacerda defendia como único meio de combater esta organização social, a objeção de consciência, seja recusando o serviço militar, negando o trabalho na fabricação de armamentos, ou na proteção aos objetores e assistência aos desertores. Às mulheres caberia a sua emancipação através da educação juntamente à resistência passiva: a greve dos ventres, com vistas à maternidade consciente (conceito desenvolvido em outras obras da autora, como Religião do Amor e da Belleza (1929) e Amai e... não vos multipliqueis (1932)). Lembremos também que Moura publicou Serviço militar obrigatório para a mulher? Recuso me... (1933), em que, como o título indica, critica a suposta “emancipação" feminina devido à sua entrada no mundo bélico.

Há também um capítulo em Civilização, tronco de escravos em que Moura recusa uma corrente recebida, que prometia boa sorte àqueles que a repassavam. Maria Lacerda desconfia da promessa e faz críticas àqueles que repassam mensagens sem raciocinar ou questionar o que está escrito, questão tão recente nas fakenews dos dias atuais. 
Além dos quinze capítulos que integram a primeira edição da obra, a nova edição conta com uma apresentação das organizadoras, um prefácio de Diva do Couto Gontijo Muniz, historiadora engajada na historiografia das mulheres e suas experiências, e três crônicas de Maria Lacerda de Moura publicadas no jornal O Malho entre os meses de Outubro de 1935 e Março de 1936: Animaes selvagens... Animaes domesticos...; a crônica altamente irônica, intitulada Saudades da minha infancia ... Da minha infancia querida ...; e uma crônica a respeito do amor, cujo título apresenta um dos lemas da autora: Só para amar foi feita a vida ...

Para o anarquismo individualista proposto por Maria Lacerda de Moura, a crítica à organização social e do trabalho não basta. A melhoria nas condições materiais de vida da classe trabalhadora não são suficientes ao seu projeto revolucionário. Que as necessidades básicas sejam supridas é condição básica e inegociável, mas conjuntamente a isto, importa que os indivíduos busquem também a sua felicidade - e se responsabilizem por isso. Não é possível, assim, uma reestruturação ética e uma vida plena na convivência com desigualdades sociais. Todavia não são caminhos que se trilham separados, nem deve-se colocar ênfase em um e postergar o seguimento do outro. É necessário o cruzamento entre uma crítica econômica e uma crítica ética.

A obra de Maria Lacerda de Moura cumpriu esse papel. Em seus escritos, a anarquista afirmou a necessidade de revolucionar toda a sociedade, e para isso, recusou a violência implícita nos discursos e práticas civilizatórias em busca do "progresso". O exercício do saber científico deveria estar alinhado à prática do apoio mútuo e da solidariedade. Viver de modo libertário seria uma tarefa para o agora, numa constante reinvenção de si e do seu entorno, a fim de edificar uma nova cultura da natureza e do viver que não alimentem os ciclos de dominação que fundamentam essa sociedade.

Nesse sentido, Civilização, tronco de escravos apresenta-se, em sua nova edição, como uma obra de grande relevância para as reflexões atuais, e tem a sua importância reforçada através das considerações de Patrícia Lessa, Cláudia Maia e Diva do Couto Gontijo Muniz. O acréscimo das três crônicas ao final da edição, possibilita-nos o encontro com outra face de Maria Lacerda de Moura. A atualidade dos seus pensamentos pulsa nas lutas do presente e ecoa nos anseios daqueles/as que sonham mundos de liberdade. 